\title{
Models, manifestation and attribution of climate change
}

\author{
Hans von Storch, Dennis Bray \\ Institute of Coastal Research, Helmholtz Zentrum Geesthacht, Max-Planck-Straße 1, 21502 Geesthacht, Germany, \\ e-mail:hvonstorch@web.de,dgbbray@gmail.com
}

\begin{abstract}
Results from a series of five surveys among five groups of international climate scientists about their evaluation of elements of climate models and of climate change are presented. The first survey was done in 1996, the latest in 2015/16. Thus, our snapshots of the opinions of climate scientists cover 20 years. The results describe a strong increase in agreement concerning issues of manifestation of climate change, i.e., that the warming is real and not influenced by changing measuring and reporting practices, and concerning attribution of this ongoing climate change to ongoing anthropogenic causes. On the other hand, the evaluation of the climate models has changed little in the past 20 years. There are still significant reservations with the models ability to incorporate clouds and to describe rainfall.

Obviously the growing conviction of ongoing man-made climate change is based on a variety of explanations, with modelling not being the predominant line of evidence. We suggest that it may be the repeated assessments by the IPCC, based on paleoclimatic evidence and stringent statistical analysis of the instrumental record which have led to the growing consensus of the warming and its causation.

We stress that the presented results concern the opinion of climate scientists with a rather broad background. Our results do not assess if the opinions of the surveyed scientists are "valid" or "right", but they recognize the character of science being a social process.
\end{abstract}

Keywords: survey, climate change, models, climate scientists

Submitted 25 July 2016, revised 8 November 2016, accepted 28 November 2016

\section{Introduction}

A growing body of literature is documenting that the climate-science community is more and more convinced that climate change is real ("manifestation") and that any explanation of this change must include elevated atmospheric greenhouse gas concentrations as a main cause of this change ("attribution"). While the numbers deviate from study to study (e.g., Oreskes 2004; Lichter 2008; Doran, Zimmermann 2009; Bray 2010), the tendency towards a growing consensus is not contested (Bray 2010).

In this study, we examine if this growing consensus on manifestation and attribution may be traced back to a growing satisfaction with a key methodology of climate sciences, namely dynamical modelling. Using the results of a time series of surveys conducted in 1996, 2003, 2008, 2013 (Bray, von Storch 1999, 2007, 2010, 2014), we first revisit the growing consensus on attribution and manifestation of climate change over a 20 year period and then the changing perceptions of climate scientists concerning the evaluation of elements of climate models in terms of model skills.

After having found that the growing agreement among climate scientists on manifestation and attribution is not matched by a similar trend in the assessment of the skill of climate models, we speculate that the role of models as an explanatory argument may be less significant than the evolving IPCC assessments since 1990, which expressed more and more confidence in the anthropogenic character of ongoing and expected climate change. This growing confidence seems to be driven mostly by more data and their statistical analysis and paleoclimatic evidence.

\section{Data and Methods}

The data employed in this analysis are drawn from surveys of the perceptions of climate scientists 1996, 2003, 2008,2013 , and 2015/16. Here we show some key aspects of the surveys; further details are given in the Appendix and the detailed reports by Bray and von Storch (2007, 2010, 2014, 2016). The questions employed in the first survey in 1996 were designed from in-depth interviews with prominent climate scientists of the time (Bray, von Storch 1996). In the following questionnaires some questions are added and others deleted. Some questions required minor rewording for the purpose of this analysis to ensure that wording remained consistent for all four surveys. The rewording did not alter the meaning.

The respondents were asked to express their opinion based on a 7 point Likert scale, for example: 1 counted as 
"not at all", "strongly disagree" or "very inadequate", and 7 meant "very much", "strongly agree" or "very adequate".

For the first (1996) survey, the questionnaire was distributed among climate scientists in 5 countries: Germany, the USA, Canada, Denmark and Italy. The questionnaire featured 74 questions, motivated by interviews with about 30 active climate scientists in the US and in Germany (Bray, von Storch 1996). The sample of North American respondents was drawn from the EarthQuest mailing list according to institutional and disciplinary affiliations. The sample of 450 German scientists was drawn from the mailing list of the Deutsche Meteorologische Gesellschaft and, for reasons of confidentiality, also distributed by the DMG. A further 50 questionnaires were distributed at the Max-Planck-Institute of Meteorology in Hamburg. The Danish Meteorological Society handled distribution in Denmark and the Osservatorio Astronomico di Roma the Italian sample. The overall response rate of the survey was approximately $40 \%(n=546)$. For further details refer to Bray and von Storch $(1999,2007)$.

The survey was repeated in 2003 and conducted by electronic means, with responses forthcoming from 30 countries. An invitation to participate in the survey was posted in the Bulletin of the American Meteorological Society, the Climlist server, and was sent to institutional lists in Germany and Denmark. Consequently a response rate could not be calculated as the target population was unknown, however, the total number of responses was 558. For further details refer to Bray and von Storch (2007).

The 2008 survey employed a non-probability convenience sample. Three lists were employed in constructing the sampling frame. List one consisted of a list of authors drawn from climate journals with the 10 highest IS impact ratings for the last 10 years. The second list consisted of the authors who contributed to the conclusions of Oreskes (2004). A third list was drawn from email lists on institute web sites (i.e. NCAR, MPI, AMS, etc.).This resulted in a list of 2059 unique respondents. Response rate was approximately $19 \%(n=375)$. For further details refer to Bray and von Storch (2010).

In 2013, the Climlist mailing list and the IPCC contributors list were added to the sample list used in 2008, resulting in an invitation list of 4491. Response rate was $7 \%(n=286)$. Responses were forthcoming from 35 countries. While a low response rate, a significant amount of literature pertaining to the response rates and sample validity of on-line surveys suggests that the response rate of $7 \%$ could be considered as adequate (c.f. Viser et al. 1996; Holbrook et al. 2007; Hamilton 2010). For further details refer to Bray and von Storch $(1999,2014)$.
In 2015 the survey sample was drawn from an updated version of the 2013 mailing list. Invitations to participate in the survey were sent by email to 3879 valid email addresses. The survey ran from mid-December 2015 until the end of January 2016. There were 651 responses for a response rate of approximately $17 \%$.

The surveys constitute a time series of data, not a panel study in which the same participants are repeatedly surveyed. We feel this approach was more likely to capture aggregate of scientific perspectives as they changed or did not change over time. Each survey contained a series of same or similar questions designed to capture a similar measure throughout all five surveys, in addition to sections unique to each particular survey. As each successive survey contained the original mailing list plus additional sample groups, it is likely that many of the respondents were included in successive surveys, but this was not by design. As the membership of the scientific community would be subject to change, by both attrition and new scientists entering the science over the twenty year period which the surveys spanned, we considered our sampling method to be the best strategy to compile a time series of perspectives. This allowed us to collect the perspectives of scientists benefiting from the body of literature as it was created and as perspectives evolved or remained the same over time. As the finite number of scientists working in climate science is not ascertainable at any given time, the total number of practicing climate scientists remained unknown making representation of any sample unattainable. However, given the sample size and the established principles of sampling, the number of respondent to the survey can be considered representative.

All data is presented in the form of box plots. Box plots illustrate the median and the spread of the data values, providing a visual assessment of the degree of consensus. Lowest and highest values are indicated by 'whiskers' extending from the boxes. The boxes contain the $50 \%$ of the total values falling between the $25^{\text {th }}$ and $75^{\text {th }}$ percentile, meaning that $50 \%$ of the cases have values within the box, $25 \%$ have values equal to or larger than the upper value of the box and $25 \%$ have values equal to or smaller than the lower boundary. The length of the box indicates how much spread there is in the data values within the middle 50 percentile. The length of the box is considered to represent a range of conservative scientific opinions and the location of the box is considered to represent the level of assessment. Outliers, if any, are represented in the figures as asterisks outside of the areas contained within the whiskers. Outliers are points that are 1.5 times the interquartile range above the third quartile or 1.5 times the interquartile range below the first quartile. 


\section{Analysis of Responses}

Figure 1 shows the changing views of the climate science community concerning issues of the manifestation of climate change and the contribution of anthropogenic causes (attribution) to climate change. Manifestation implies the belief that climate change is currently occurring, whether naturally or as the result of anthropogenic causes. Attribution refers to the assessment that most of the contemporary or near future change in climate is, or will be, the result of human activity.

The present assessment of the IPCC on these matters is provided by the IPCC $5^{\text {th }}$ Assessment $»$ More than half of the observed increase in global mean surface temperature (GMST) from 1951 to 2010 is very likely due to the observed anthropogenic increase in greenhouse gas (GHG) concentrations [and] It is extremely likely that human activities caused more than half of the observed increase in GMST from 1951 to 2010. This assessment is supported by robust evidence from multiple studies using different methods. Observational uncertainty has been explored much more thoroughly than previously and the assessment now considers observations from the first decade of the $21^{\text {st }}$ century and simulations from a new generation of climate models that have the ability to simulate historical climate that are improved in many respects relative to the previous generation of models considered in AR4«.

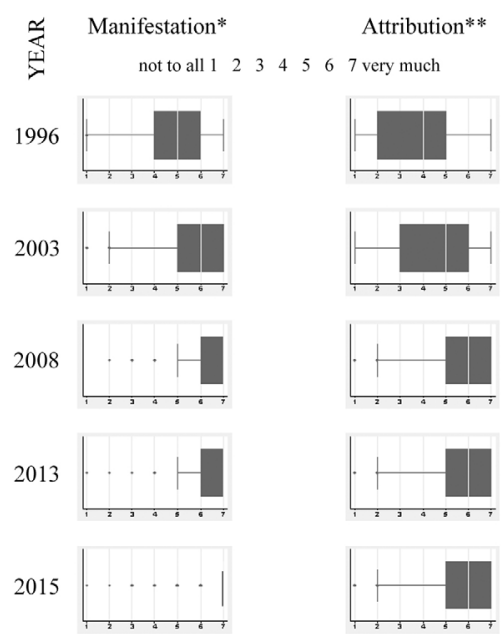

Fig. 1. Manifestation and attribution

Question wording varies slightly depending on year of survey. *1996, 2003. Manifestation: We can say for certain that global warming is a process already underway.

*2008, 2013. Manifestation: How convinced are you that climate change, whether natural or anthropogenic, is occurring now?

**1996, 2003. Attribution: Climate change is mostly the result of anthropogenic causes.

**2008, 2013, 2015. Attribution: How convinced are you that most of recent or near future climate change is, or will be, a result of anthropogenic causes?
The belief that (natural or man-made) climate change is occurring was already relatively strong in the first survey, particularly if one considers that only a value of one indicates that climate change is not happening at all (see Fig. 1). Between 1996 and 2008 this belief has gradually increased to where consensus indicates that there is little doubt in the scientific community that climate change is occurring. There is no change between 2008 and 2013. In summary, one could conclude that currently there is very little doubt that climate change is underway.

As to the causes of climate change (attribution) the initial limited agreement (in 1996, with a mean of a little less than the central 4), that human influence is a major factor, has increased over time similarly to the increase of the belief in manifestation. Not surprisingly, the agreement to the assertion that the cause behind the warming may be attributed to anthropogenic causes is somewhat smaller than the agreement on manifestation. The agreement to the latter, manifestation is a condition for agreement with attribution. Thus the former group must be larger than the latter. Nevertheless the agreement on attribution is very large, with about $90 \%$ of respondents answering with a value of 5-7 in 2007, 2013, and 2015/16.

Thus the belief that climate change is occurring and that it is the result of anthropogenic causes increased significantly between 1996 and 2008 and has remained mostly constant since 2008. As such one would expect a perception of advances in the abilities of climate models and the understanding of the physical processes of the climate to follow a similar pattern. However as Fig. 2 and 3 indicate, this has not been the case.

Figure 2 depicts a time series of the assessment of climate models dealing with two significant "drivers", i.e., external factors, which may influence climate, namely land surface changes and the changing presence of greenhouse gases in the atmosphere. Of particular importance is "greenhouse gases", given the assessment of the consensus that they are, or will be, the dominant cause of climate change. The data indicate that the assessment of how well models can deal with greenhouse gases has steadily increased in confidence. However, the assessment of lands surface influences indicates that there is room for significant improvement.

Figure 3 deals with the skill of describing the effect of internal processes in climate models adequately, namely hydrodynamics and radiation that are reasonably well understood and clouds and precipitation, two processes that are typically described as problematic. Only the confidence in radiation and precipitation has marginally advanced. The skill of describing the other processes dealt with in Fig. 3, hydrodynamics, radiation and clouds is per- 


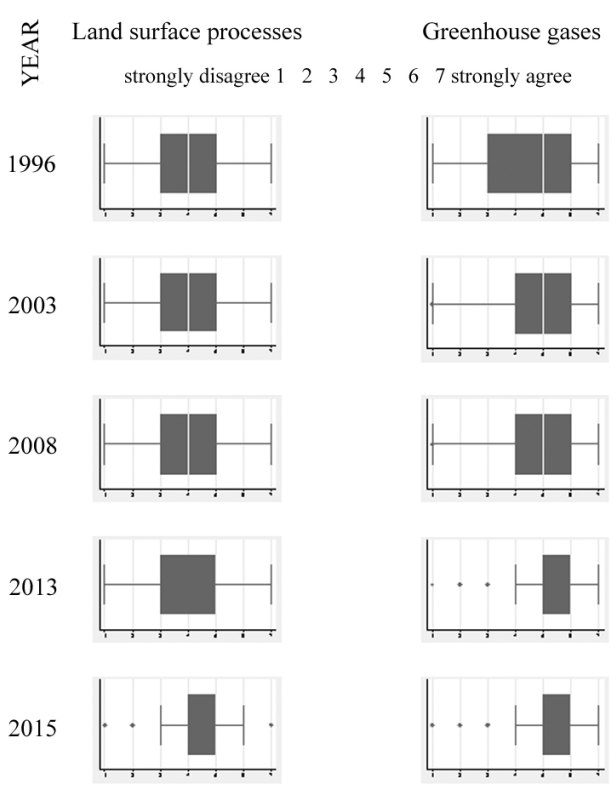

Fig. 2. Incorporation of drivers in climate models Respondents were asked to indicate a level of agreement with the following statement «The current state of scientific knowledge is developed well enough to allow for a reasonable assessment of...«; responses were based on a 7 point Likert Scale: 1 = Strongly Disagree, 7 = Strongly Agree; '.' = outlier

ceived by the climate science community to have remained relatively stagnant since 1996 . While the assessment of the ability of climate models to deal with radiation contains little doubt that models do a good job, there appears to be a consensus that there is room for improvement in model abilities to handle clouds and precipitation.

We point to the reluctance of climate scientists to label the skills of models in describing internal processes (Fig. 3) and external drivers (Fig. 2) as perfect (on the Likert scale: 7). This reluctance may reflect the optimism of scientists that any tool can be improved.

\section{Conclusion}

The overarching statements emanating from the now five IPCC assessment reports indicate a rising level of confidence in both manifestation and, with particular emphasis, attribution. The 1990 First Assessment Report of the IPCC suggests that continued GHG emissions would enhance the greenhouse effect. The 1996 Second Assessment Report (IPCC 1996) suggested, in a somewhat stronger manner than in $1990 »$ the balance of evidence suggests that there is a discernible human influence on global climate«. In the 2001 Third Assessment report (IPCC 2001) statements included that »over the last century, the Earth has warmed by 0.6 degrees Celsius, and the increase is at least partly due to the anthropogenic release of GHGs«. AR4 (IPCC 2007) reports »The un-

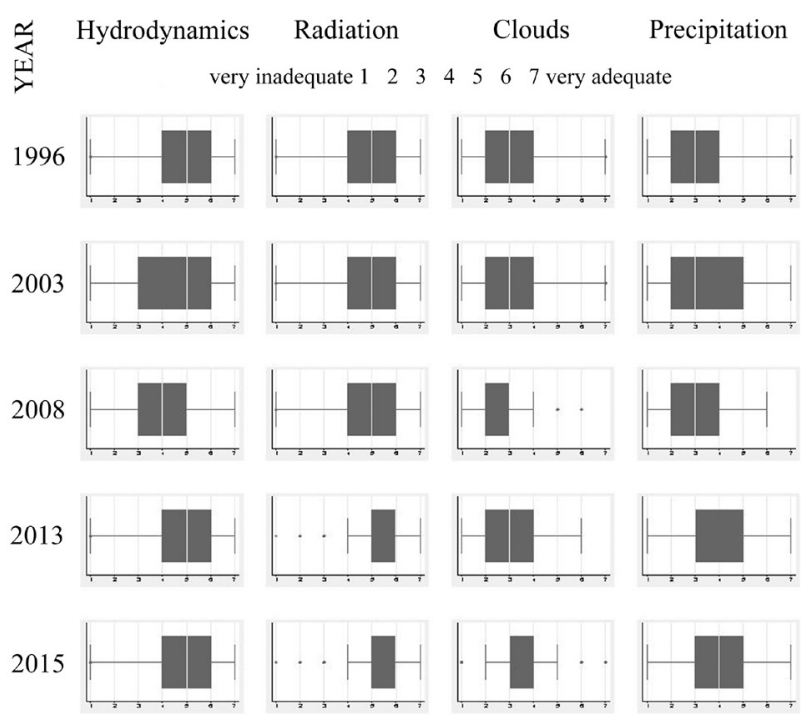

Fig. 3. Skill of climate models

Respondents were asked «How well do you think atmospheric models can deal with Hydrodynamics, Radiation, Clouds, Precipitation «; responses were based on a 7 point Likert Scale: $1=$ Very inadequate, 7 = Very adequate; ' '’= outlier

derstanding of anthropogenic warming and cooling influences on climate has improved since the TAR, leading to very high confidence that the global average net effect of human activities since 1750 has been one of warming... «. By 2013 (IPCC 2013) the message from the IPC was »It is extremely likely [95 percent confidence] more than half of the observed increase in global average surface temperature from 1951 to 2010 was caused by the anthropogenic increase in greenhouse gas concentrations and other forcing together «. Thus, there is growing strength in the conviction of the IPCC statements concerning manifestation and attribution concerning climate change that is consistent with the claims of climate scientists as presented in Fig. 1.

The fact that climate models respond with a temperature increase (and other changes) to elevated greenhouse gas concentrations is often perceived, at least in the public, as the key "evidence" in support of the claims of human induced climate change. Our analysis - namely the parallel development in the climate-scientific community of growing confidence in the diagnosis of manmade climate change, and of almost stagnant confidence in the skill of such models - demonstrates that in scientific circles, this simple argument is not realistic. Instead other evidence, independent of the skill of models, must have persuaded the scientific community to accept the explanation of manmade causes for the ongoing change.

The AR4 IPCC report claims that advances are based on »improvements in understanding processes and their simulations in models $\ll$ is contrary to the assessment made 
by the scientific community, however the reasons for such are beyond the scope of this paper.

By AR5, the overarching statement of the report reads "The Working Group I contribution to the IPCC's Fifth Assessment Report (AR5) considers new evidence of climate change based on many independent scientific analyses from observations of the climate system, paleoclimate archives, theoretical studies of climate processes and simulations using climate models«. Advances in "observations" and "paleoclimate" might explain the scientific community's levels of consensus concerning manifestation and attribution while at the same time, the lack of perceived advancement in the understanding of physical processes related to climate change.

The results of our surveys do not include an assessment of what other factors might contribute to the scientific levels of consensus among our respondents. Consequently, we can only offer speculation.

We speculate that the increasing confidence among scientists comes foremost from the IPCC assessment but also from progress in paleoclimatic reconstructions of the climate, mainly of the past 1000 to 2000 years. The paleoclimatic evidence was hotly contested and discussed (e.g., Mann et al. 1998; von Storch et al. 2004; NRC 2006), and appeared later as less obvious proof of recent unprecedented warming, but is still consistent with the diagnosis of changes which need an explanation beyond internal variability (detection). Over the years, observational uncertainty has been explored much more thoroughly than previously and the assessment now considers observations from the first decade of the $21^{\text {st }}$ century and simulations from a new generation of climate models whose ability to simulate historical climate has improved in many respects relative to the previous generation of models considered in AR4.

A more important development was the steadily more successful "detection and attribution" analysis of the instrumental record, whether recent changes (multidecadal trends for example) would remain within the range of natural variability (detection) and, if not, which mix of external factors would result in most plausible explanations (attribution), originally suggested by Klaus Hasselmann (1993) and implemented in the IDAG group (Pennell et al. 1993; Barnett et al. 2005).

While the detection and attribution is an exercise of assessing the instrumental record, in many cases among the nuts and bolts of these procedures, model output has a certain significance, namely in providing estimates of natural variability and in optimization of signal-to-noise ratios by using model-generated response patterns to given external drivers (e.g., Hegerl et al. 1996). In more recent years, when the signal-to-noise ratio improved, less sophisticated methods were sufficient for detection (e.g. Rybski et al. 2006).

\section{Bibliography}

Barnett T., Zwiers F., Hengerl G., Allen M., Crowly T., Gillett N., Hasselmann K., Jones P., Santer B., Schnur R., Scott P., Taylor K., Tett S., 2005, Detecting and attributing external influences on the climate system. A review of recent advances, Journal of Climate, 18, 1291-1314, DOI: 10.1175/JCLI3329.1

Bray D., 2010, The scientific consensus of climate change revisited, Environmental Science \& Policy, 13 (5), 340-350, DOI: 10.1016/j.envsci.2010.04.001

Bray D., von Storch H., 1996, Inside science - a preliminary investigation of the case of global warming, Max-Planck-Institut für Meteorologie, Report No 195, 58 pp., available at: http:// www.academia.edu/2369025/Inside_science_-_a_preliminary_investigation_of_the_case_of_global_warming (data access 14.12.2016)

Bray D., von Storch H., 1999, Climate science: an empirical example of postnormal science, Bulletin of American Meteorological Society, 80 (3), 439-455, DOI: 10.1175/1520-0477 (1999)080<0439:CSAEEO>2.0.CO;2

Bray D., von Storch H., 2007, Climate scientists' perceptions of climate change science, Report No 11, GKSS - Forschungszentrum Geesthacht GmbH, 128 pp., available at: http:// www.hvonstorch.de/klima/pdf/GKSS_2007_11.pdf (data access 14.12.2016)

Bray D., von Storch H., 2010, CliSci2008: a survey of the perspectives of climate scientists concerning climate science and climate change, Report No 9, GKSS - Forschungszentrum Geesthacht $\mathrm{GmbH}, 121$ pp., available at: https://ncse. com/files/pub/polls/2010--Perspectives_of_Climate_Scientists_Concerning_Climate_Science_\&_Climate_ Change_pdf(data access 14.12.2016)

Bray D., von Storch H., 2014, A survey of the perceptions of climate scientists 2013, HZG Report 4, Helmholtz-Zentrum Geesthacht, 114 pp., available at: https://www.hzg.de/impe$\mathrm{ria} / \mathrm{md} /$ content/hzg/zentrale_einrichtungen/bibliothek/berichte/hzg_reports_2014/hzg_report_2014_4.pdf (data access 14.12.2016)

Bray D., von Storch H., 2016, The Bray and von Storch $5^{\text {th }}$ International Survey of Climate Scientists 2015/2016, HZG Report 2, Helmholtz-Zentrum Geesthacht, 143 pp., available at: https://www.hzg.de/imperia/md/content/hzg/zentrale_einrichtungen/bibliothek/berichte/hzg_reports_2016/hzg_report_2016_2.pdf (14.12.2016)

Doran P.T., Zimmermann M.K., 2009, Examining the scientific consensus on climate change, EOS, 90 (3), 22-23, DOI: 10.1029/2009EO030002 
Hamilton M., 2010, Online survey response rates and times. Background and guidance for industry, available at: https:// www.hitpages.com/doc/5231534575452160/1\#pageTop (data access 14.12.2016)

Hasselmann K., 1993, Optimal fingerprints for the detection of time dependent climate change, Journal of Climate, 6, 19571971, DOI: 10.1175/1520-0442(1993)006<1957:OFFTDO> 2.0.CO;2

Hegerl G., von Storch H., Hasselmann K., Santer B.D., Cubasch U., Jones P.D., 1996, Detecting anthropogenic climate change with an optimal fingerprint method, Journal of Climate, 9, 2281-2306, DOI: 10.1175/1520-0442(1996)009<2281:DGG ICC $>2.0 . \mathrm{CO} ; 2$

Holbrook A., Krosnick J., Pfent A., 2007, The causes and consequences of response rates in surveys by the new media and government contractor survey research firms, [in:] Advances in telephone survey methodology, J.M. Lepkowski, N.C. Tucker, J.M. Brick, E.D. DeLeeuw, L. Japec, P.J. Lavrakas, M.W. Link, R.L. Sangster (eds.), Wiley, New York, 499-528

IPCC, 1990, Climate change. The IPCC scientific assessment, A Report of the Intergovernmental Panel on Climate Change, J.L. Houghton, G.J. Jenkins, J.J. Ephraums (eds.), Cambridge University Press, 365 pp., available at: https://www. ipcc.ch/ipccreports/far/wg_I/ipcc_far_wg_I_full_report.pdf (data access 14.12.2016)

IPCC, 1996, Climate change 1995. The science of climate change, Contribution of Working Group I to the Second Assessment Report of the Intergovernmental Panel on Climate Change, J.T. Houghton, L.G. Meira Filho, B.A. Callander, N. Harris, A. Kattenberg, K. Maskell (eds.), Cambridge University Press, 572 pp., available at: https://www.ipcc.ch/ipccreports/sar/wg_I/ipcc_sar_wg_I_full_report.pdf (data access 14.12.2016)

IPCC, 2001, Climate change 2001: The scientific basis, Contribution of Working Group I to the Third Assessment Report of the Intergovernmental Panel on Climate Change, J.T. Houghton, Y. Ding, D.J. Griggs., M. Noguer, P.J. van der Linden., X. Dai, K. Maskell, C.A. Johnson (eds.), Cambridge University Press, 94 pp., available at: http://www.grida.no/climate/ ipcc_tar/wg1/pdf/WG1_TAR-Front.pdf(14.12.2016)

IPCC, 2007, Climate Change 2007: The Physical Science Basis, Contribution of Working Group I to the Fourth Assessment Report of the Intergovernmental Panel on Climate Change, S. Solomon, D. Qin, M. Manning, Z. Chen, M. Marquis, K.B. Averyt, M. Tignor, H.L. Miller (eds.), Cambridge University Press, 996 pp., available at: http:// www.ipcc.ch/pdf/assessment-report/ar4/wg1/ar4_wg1_ full_report.pdf (data access 14.12.2016)

IPCC, 2013, Climate change 2013: The physical science basis, Contribution of Working Group I to the Fifth Assessment Report of the Intergovernmental Panel on Climate Change, T.F Stocker, D. Qin, G.-K. Plattner, M. Tignor, S.K. Allen, J. Boschung, A. Nauels, Y. Xia, V. Bex, P.M. Midgley (eds.), Cambridge University Press, Cambridge, United Kingdom and New York, NY, USA, 1535 pp., available at: http://www. climatechange2013.org/images/report/WG1AR5_ALL_FINAL.pdf (data access 14.12.2016)

Lichter S.R., 2008, Climate scientists agree on warming, disagree on dangers, and don't trust media's coverage of climate change, STATS, 24 April, available at: https://web.archive. org/web/20080512001714/http://www.stats.org/stats_articles.htm (data access 14.12.2016)

Mann M., Bradley R.S., Hughes M.K., 1998, Global-scale temperature patters and climate forcing over the past centuries, Nature, 392, 779-789, DOI: 10.1038/33859

NRC, 2006, Surface temperature reconstructions for the last 2,000 years, National Research Council of the National Academies, The National Academies Press, Washington, D.C., 145 pp., available at: https://climatechangelive.org/img/fck/file/surftemps2000yrs.pdf (data access 14.12.2016)

Oreskes N., 2004, Beyond the ivory tower: the scientific consensus on climate change, Science, 306 (5702), 1686, DOI: 10.1126/science. 1103618

Pennell W., Barnett T.P., Hasselmann K., Holland W.R., Karl T., North G.R., MacCracken M.C., Moss M.E., Pearman G., Rasmusson E.M., Santer B.D., Smith W.K., von Storch H., Switzer P., Zwiers F.W., 1993, The detection of anthropogenic climate change, [in:] Proceedings of the $5^{\text {th }}$ Symposium on Global Change Studies, American Meteorological Society, Jan. 17-22, Anaheim, California, 21-28

Rybski D., Bunde A., Havlin S., von Storch H., 2006, Longterm persistence in climate and the detection problem, Geophysical Research Letters, 33 (6), L06718, DOI: 10.1029/2005GL025591

Visser P.S., Krosnick J.A., Marquette J., Curtin M., 1996, Mail surveys for election forecasting? An evaluation of the Columbus Dispatch poll, Public Opinion Quarterly, 60 (2), 181227, DOI: $10.1086 / 297748$

von Storch H., Zorita E., Jones J., Dimitriev Y., González-Rouco F., Tett S., 2004, Reconstructing past climate from noisy data, Science, 306 (5696), 679-68, DOI: 10.1126/science.1096109 